\title{
User's Acceptance on e-Hailing System as Alternative Transportation by Using Modal Shift
}

\section{Muhammad Azmie Nazri ${ }^{1}$, Kamarudin Ambak ${ }^{*}$, Ahmad Raqib Ab Ghani ${ }^{1}$, Muhamad Razuhanafi Mat Yazid ${ }^{2}$}

${ }^{1}$ Smart Driving Research Center, Faculty of Civil Engineering and Built Environment,

Universiti Tun Hussein Onn Malaysia, 86400 Parit Raja, Batu Pahat, Johor, MALAYSIA

${ }^{2}$ Department of Civil Engineering, Faculty of Engineering and Built Environment, Universiti Kebangsaan Malaysia, 43600 Bangi, Selangor, MALAYSIA

*Corresponding Author

DOI: https://doi.org/10.30880/ijie.2021.13.03.013

Received 20 December 2020; Accepted 01 May 2021; Available online 06 June 2021

\begin{abstract}
Hailing system is one of the mediums that are functioning to minimize the person on using the private transportation. Due to modern technology era, internet is used to ease the user in communication. With the internet platform assist, the e-Hailing system has well in management with the users can request the destination, travel time and also the cost for this service. The objective of this study was to identify the contributing factors effect to use eHailing system and also to analyze modal shift between public transport and e-Hailing system. Therefore, a study towards user's acceptance on using e-Hailing system as alternative transport based on the modal shift method with Binary Logistic regression analysis was necessary to identify factor and effect that influence modal shift occur from public transport to the alternative transport which is e-Hailing system. Johor Bahru area was the selected area as the location of the study due popular with the e-Hailing system. This study also shows the type of e-Hailing system that is used and will know the how this system really works with the safety, cost and also travel time. The binary logistic regression analysis shows that all the components were positively significant. This alternative transport is actually sending the user to the destinations that are selected by the user in the application. Therefore, the e-Hailing system is an alternative transport that must be used for people nowadays.
\end{abstract}

Keywords: e- Haling, modal shift, alternative transportation

\section{Introduction}

In Malaysia, public transport has important role for the person who do not own or not able to drive their private transport. As increasing demand for transportation, alternative ground transportation options have evolved including bike, personal car, bus, taxi and also subway transit. Compared to the other transports, taxi is the important part of mobility in the new era. Taxi industry are the one of the top mode of transportation in the country for more than 50 years [1]. In using the e-Hailing system as the alternative transport, the amount of car use on the road can be reducing as the transports also donate to pollution. The transport sector accounts for $23 \%$ of global CO2 emissions, most of which are due to fossil fuel burning. The sector's significant contribution to global greenhouse gas emissions has made it an increasing area of study and concern. Efforts to reduce carbon emissions will also be challenged by transport sector forecasts of 25 percent growth by 2030 [2], [3]. The disturbing issues that always occur about the public transport especially taxi are surge pricing, unfair competition, safety concern, working hours and the difficulties on catching taxis [4]. 
Cost is the one of problem that always become the decrease number of users wants to change from using taxi to e-Hailing system. As we all know, the main cause of problem is because of the unsuitable taxi fare system [5]. The amount of the fare is not stable and has not fixed charge. The fare of the taxi is not be stated like the e-Hailing system and will be reveal after the users arrive at the destination. The two objectives of this study are to identify the contributing factor that effect to use e-Hailing system and to analyse the modal shift between public transport and eHailing system. There are three selected areas for the study which are Tebrau, Skudai and Kulai as the location of study at Johor Bahru which is the area that popular with e-Hailing system and also public transport. Johor Bahru is the one of the urban areas with the high amount of population. So, in collecting the data at Johor Bahru, the trend of data will be positive. The survey only target to the person use the e-Hailing system as their alternative transport than the public transport.

Public transportation demand has generally increased rapidly from year to year. Because of traffic congestion issues and more environments, public transport has become necessary for their lifestyle mainly in urban areas. The government of Malaysia strongly recommends the use of public transport to reduce traffic flow, the rate of accidents and also in reducing the cost of higher petrol charge [6]. Public transport has several advantages which are environmental sustainability and fossil fuel use reduction, building a strong economy by transporting people to and from work, maintaining and creating jobs, preventing congestion and also providing access for all ages. Grab Car is a technology company that provides transportation services using a mobile application. Grab Car App is an application that enables users to easily get a taxi through online and mobile platforms. They help with car booking and searching for car location. The application is also commonly used in countries in South-East Asia, such as Malaysia. Grab is a technology company that through its app provides a wide range of ride and logistics services. Grab application has been downloaded from Southeast Asia to over 45 million mobile devices [7]. The objective of this research is to identify the contributing factors effect to use e-Hailing system and also to analyse modal shift between public transport and eHailing system.

\section{Method and Materials}

This research is start with problem identification and determines the location of the study. When the location is identified, approach to the resident to fill the questionnaire and also proceed with the pilot study. The raw data that be obtain was being process and in making the data analysis and result. The final step is processing for the discussion and makes the conclusion for this research.

\subsection{Instrument and Measurement}

At the first stage which is the beginning stages of this study was identifying the contributing factors that affect the users on using e-Hailing system as alternative transport and determine the medium that can increase the attraction of the resident on using e-Hailing system as alternative transport. Johor Bahru was selected as the location because of the popularity in public transport and e-Hailing system at that area. A very important task which was identifying the suitable location based on the time, environment and others. This suitable location also has assist on getting a positive result and also achieved the objective. In order to achieve the good result for the questionnaire, the research questionnaire must be design properly to get a relevant answer and also applicable in achieving the objective of the research. The questionnaire was designing in both languages which are English and Malay. This step eases the respondent to understand the question and answer the form smartly. In this research, the questionnaire have been design into four parts which are part A-Demographic [8], part B-Respondent's experience [9], part C-Perception of e-Hailing system user's [10] and part D-State preference survey [10].

\subsection{Sample Size and Data collection}

In order to construct a result of descriptive statistic multivariate analysis and structural equation model the sample size is practically sufficient. The overall population in Johor Bahru area is approximately 802489 per year in 2019. The increasing of the population due to the area that becomes tourist attraction. So, the table show that in order to achieve good result in our research, the sample size that use is 384 based on Table 1 below. Hence for this study, a total sample size which is 200 had been determined.

A pilot study also called as pilot experiment which was a small-scale preliminary study conducted and gather Information prior to a larger study, in order to improve the quality and efficiency of questionnaire. In this study, 20 questionnaires were distributed as pilot study to public who use the e-Hailing system. Before actual data collection activity done, a prefix test or better known as pilot studies have been conducted to ascertain the questions inside. The questionnaire is easy to understand and easy answered by respondent. Preliminary testing is conducted for to identify if there are errors or mistakes in the instrumentation design conducted for allows researchers to correct them before applies in real studies [3], [11]. A pilot study can reveal design questionnaire weakness such as the question hard to understand, the poor instruction and procedure.

The result of the pilot study is shown in the Table 1 for Part $\mathrm{C}$ and Table 2 for Part $\mathrm{D}$ of the questionnaire. The values of Alpha Cronbach that obtain were pass for the next step of distributing questionnaire. 
Table 1 - Reliability statistic for Part C

\begin{tabular}{cc}
\hline Cronbach's Alpha & N of Items \\
\hline 0.905 & 10 \\
\hline
\end{tabular}

Table 2 - Reliability statistic for Part D

\begin{tabular}{cc}
\hline Cronbach's Alpha & N of Items \\
\hline 0.857 & 10 \\
\hline
\end{tabular}

\subsection{Analysis and Tools}

The logistic model or also known as logit model was used as a final model to investigate mode choice behaviour of travellers to highlight the trend of the travellers when considering their mode of transport. The proposed model used to predict the relationship between dependent variables is evaluated based on the following equation [11]:

$$
y=\frac{1}{1+e^{-f(x)}}
$$

where $f(x)$ is an analytic function in $x$. With this choice, the single layer network is identical to the logistic regression model.

Binary logistic regression analysis is performed with the aim to determine the parameter affecting the sustainable mode choices and determine the probability of choosing a more sustainable mode of transport. The general form of logistic regression is shown on Eq. (2) and Eq. (3) [12]. Logistic regression function,

$$
p(y)=\frac{e^{v_{\text {diff }}}}{1+e^{v_{\text {diff }}}} \geq 0
$$

Determine term $\mathrm{V}_{\text {diff }}$ is assumed to be a given by a linear in parameters specification. Accordingly, the linear regression equation:

$$
v_{\text {diff }}=a_{0}+a_{1} x_{1}+a_{2} x_{2}+a_{3} x_{3}+
$$

where, $a_{o}=$ Regression constant, $a_{1} x_{1}=$ Regression coefficients, $a_{2} x_{2}=$ Independent variable (distance travel and cost travel), $p(y)=$ Probability of predicting shifting from public transport to e-Hailing, $v_{\text {diff }}=$ Linear function of dependent variables. Therefore, the probability of shift can be given as:

$$
p_{\text {shif }}=\frac{e^{v_{\text {diff }}}}{1+e^{v_{\text {diff }}}}=\frac{e^{a_{0}+a_{1} x_{1}+a_{2} x_{2}+a_{3} x_{3}+}}{1+e^{a_{0}+a_{1} x_{1}+a_{2} x_{2}+a_{3} x_{3}+}}
$$

where $p_{\text {shift }}=$ robability of shift from public transport to e-Hailing system, $v_{\text {diff }}=$ Linear function of dependent variable (distance travel and cost travel)

The travel mode was considered as dependent variable for this research. The employment status, car ownership, gender, age of the respondents, trip length, frequency of usage and time travel difference were considered as independent variables. The following section present the binary logistic regression model develops for the employees and residents. SPSS was the software that be used for this analysis. An exploratory analysis of residents data is also be presented. A coefficient of determining $\mathrm{R}^{2}$ value was calculated to test the better of fit of the model.

\section{Results and Discussion}

The data collections are being distributed by using the questionnaire. 200 respondents were selected randomly in getting the balancing on the data collection. The questionnaire was divided into 4 parts as part A as a demographic data.

\subsection{Descriptive Analysis}

Table 3 shows the result on the demographic data. There are two type of gender that be shown in this study which are male and female. Based on the table shown, 51\% (102 respondents) were male and $49 \%$ (98 respondents) were female. This analysis data shown the number of male respondents higher than the female respondents. This is because most of the male respondents usually use the e-Hailing system as their alternative transport than public transports. The races are divided into four type of race which are Malay, Chinese, Indian and others. Majority of the users are Malay with $42.5 \%$ ( 85 respondents). Chinese located at the second higher with $27 \%$ (54 respondents) and followed by Indian $21 \%$ (42 respondents). The least users are other race category with $9.5 \%$ (19 respondents). 
For the respondent age, majority respondents were in class 21 to 30 years old with $48.5 \%$ (97 respondents). Age at 31 to 40 years old located at second higher class rank with $34 \%$ (68 respondents) followed by age above 41 with $11 \%$ (22 respondents). The least percentage is the range with age 20 years and above with $6.5 \%$ (13 respondents). The maximum percentage respondent's education level is secondary schools with the percent are $46.5 \%$ ( 93 respondents). Then, followed by university level with $29.5 \%$ (59 respondents). For the Pre-University level, the percent of respondent are 19\% (38 respondents) and lastly around 5\% (10 respondents) are finish or on the primary school for their level of education. The private sector leads the chart with a maximum percent value which is $48.5 \%$ (97 respondents). Freelance job located at second ranking with $20.5 \%$ (41 respondents) and only different $1 \%$ with the students that is $19.5 \%$ (39 respondents). Government sector are at the third ranking with the value are 6\% (12 respondents). Respondent that are not working stated at the last ranking with 5.5\% (11respondents).

From the analysed data below, stated that respondents that are in marriage status higher than single status with $60 \%$ (120 respondents) and 40\% (80 respondents) for the single status. For the respondents' salary, majority of respondent's salary is at RM2000-Rm3000 with the percent is $36.5 \%$ (73 respondents). It was followed by class salary of RM1000 to RM2000 with 32.5\% (65 respondents) and not relevant salary located at the third ranking with the percent are $21 \%$ (42 respondents). The not relevant salary comes from students and also housewives that not have salary. Salary upper than RM3000 have percent 5.5\% (11 respondents) and lower than RM1000 located at the last ranking with $4.5 \%$ ( 9 respondents).

From the demographic data that obtain, male respondents are more to use e-Hailing system than female respondents. For the race of the respondents, the maximum of the respondents is come from Malay. In addition, for the other demographic item that be investigate such as age, marriage status, education level, occupation of the respondents and also their individual salary and most of them have experience in using the e-Hailing system as their alternative transport. The location of this survey is at Johor Bahru which are urban are, so some of them come from a specific occupation and also come from students. For the salary, some of the respondent have no specific salary that come from students and also housewives. The students that be a respondent in this survey use the e-Hailing as their alternative transport because of the easy in access. From the data obtain also, majority of e-Hailing use come from the age between 21 to 30 years old with private sector as their occupation with salary RM2000 to RM3000.

The group of Generation Y and Millennial always accepting the technology and innovation [10].There are some people that come from high income family prefer to use private transport rather than public transport [13]. For the education level, most of them were well educated users because they come from secondary school and university.

Table 3 - Demographic of the respondents $(n=200)$

\begin{tabular}{|c|c|c|c|c|c|c|c|}
\hline Item & & $\%$ & Respondents & Item & & $\%$ & Respondents \\
\hline \multirow[t]{3}{*}{ Gender } & Male & 51 & 102 & $\begin{array}{c}\text { Education } \\
\text { Level }\end{array}$ & Primary & 5 & 10 \\
\hline & Female & 49 & 98 & & Secondary & 46.5 & 93 \\
\hline & & & & & Pre-University & 19 & 38 \\
\hline \multirow[t]{5}{*}{ Race } & Malay & 42.5 & 85 & & University & 29.5 & 59 \\
\hline & Chinese & 27 & 54 & & & & \\
\hline & Indian & 21 & 42 & Occupation & Student & 19.5 & 39 \\
\hline & Others & 9.5 & 19 & & Not Working & 5.5 & 11 \\
\hline & & & & & Freelance & 20.5 & 41 \\
\hline \multirow[t]{5}{*}{ Age } & $\begin{array}{l}\text { Below } \\
20\end{array}$ & 6.5 & 13 & & Private Sector & 48.5 & 97 \\
\hline & $21-30$ & 48.5 & 97 & & Government & 6 & 12 \\
\hline & $31-40$ & 34 & 68 & & & & \\
\hline & Upper 40 & 11 & 22 & Salary & Not Relevant & 21 & 42 \\
\hline & & & & & Lower 1000 & 4.5 & 9 \\
\hline \multirow[t]{3}{*}{$\begin{array}{c}\text { Marriage } \\
\text { Status }\end{array}$} & Single & 40 & 80 & & 1000 to 2000 & 32.5 & 65 \\
\hline & Married & 60 & 120 & & 2000 to 3000 & 36.5 & 73 \\
\hline & & & & & Upper 3000 & 5.5 & 11 \\
\hline
\end{tabular}

From Table 4, it stated that the means score at the higher rank is at the statement about the most of society do not know about the presence of e-Hailing System with 4.67 (68.5\%, Very Agree). Next' about the statement that users only can wait at home while waiting the e-Hailing has the second higher means score with 4.60 (61.5\%, Very Agree). For 
the statement that e-Hailing System must also have in rural areas, the means are 4.59 (65\%, Very Agree) with that followed by the same means score between the e-Hailing easy access than public with 4.58 (63.5\%, Very Agree) and eHailing can be use anytime without schedule with 4.58 (63.5\%, Very Agree). Then, the means score followed by the statement of e-Hailing system can save time than public transport with 4.55 (61\%, Very Agree). The e-Hailing is more comfort than public transport have mean 4.54 (58.5\%, Very Agree) with that statement. For the third statement which is the e-Hailing can save the cost of travel than public transport with 4.51 (61\%, Very Agree). The second last rank of mean score is the statement about the e-Hailing System is smart in management than public transport with 4.45 (54.5\%, Very Agree) and the last ranking of mean score about the e-Hailing is more safe than public transport with 3.76 (38.5\%, Very Agree).

\subsection{Respondents Mode of Choice Between Private and e-Hailing Transports}

The line graph in Fig. 1 illustrate about the two of choice which are e-Hailing and public transport. At a distance from $1 \mathrm{~km}$ to $5 \mathrm{~km}$, the percent of repondents use the e-Hailing is about $90.5 \%$ followed by the distance in between $5 \mathrm{~km}$ to $10 \mathrm{~km}$ with $90 \%$. The percent in choosing e-Hailing automatically drop when the distance increase to $10 \mathrm{~km}$ to $15 \mathrm{~km}$, $15 \mathrm{~km}$ to $20 \mathrm{~km}$ and upper than $20 \mathrm{~km}$ because of the respondent choosing public transport. this can be proved when the trend in graph for public transport increase rapidly when at that distance. The percent are about from 34\% and increase to $79.5 \%$ at distance upper than $20 \mathrm{~km}$. The figure below shows the shifting point when the respondent that shift from e-Hailing to public transport and also public transport shifted to e-Hailing system.

Table 4 - Mean and standard deviation on perception of users

\begin{tabular}{llc}
\hline \multicolumn{1}{c}{ Item } & Mean & Standard Deviation \\
\hline e-Hailing System management is more smart than public transport & 4.45 & 0.721 \\
e-Hailing System save our time than public transport & 4.55 & 0.656 \\
e-Hailing System can save cost of time travel than public transport & 4.51 & 0.665 \\
e-Hailing System is more comfort than public transport & 4.54 & 0.625 \\
\hline $\begin{array}{l}\text { Most of society do not know about the exposure of the E-Hailing } \\
\text { System }\end{array}$ & 4.67 & 0.542 \\
$\begin{array}{l}\text { e-Hailing System have easy access than public transport } \\
\text { Service of E-Hailing can use any time without schedule like public } \\
\text { transport }\end{array}$ & 4.58 & 0.629 \\
e-Hailing System also must operate at rural area and not only at & 4.58 & 0.630 \\
urban area & 4.59 & 0.611 \\
$\begin{array}{l}\text { Users only can stay at home only while waiting for the e-Hailing } \\
\text { service }\end{array}$ & 4.60 & 0.531 \\
e-Hailing is safer than the public transport & 3.76 & 1.320 \\
\hline
\end{tabular}

From the analysis data, the users change from e-Hailing to public transport when the distance of travel increase. Its look like that respondents start to shift from e-Hailing to public transport when the long journey is set. In addition, respondents tend to shift from e-Hailing system to public transport when increasing of distance occur and may be start at $15 \mathrm{~km}$ to $20 \mathrm{~km}$.

The cost of travel is the second medium in determining the effect on changing mode of transport. Fig. 2 shows the changes in trend between e-Hailing system and public transport. From the line graph, $90 \%$ respondents in choosing eHailing when the cost of travel about lower to RM5 and RM5 to RM10. Repondents start to shift from e-Hailing to public transport when the cost of travel start increase in range RM20 to RM30 and RM30 above. The trend of using eHailing decrease and the pattern in using public transport increase at that range from $65 \%$ to $78 \%$. The changes in mode of shifted from e-Hailing to public transport and also public transport to e-Hailing system are shown in figure below.

For the cost of the travel, the shifting also occurs when the cost of travel increase. Respondents tend to use public transport when the cost of travel become higher. So actually, users start to use the e-Hailing system because of the cost is much lower than the other service such as public transport. When the distance travel and also cost of travel is decrease, users that use the public transports tend to shift from public transport to e-Hailing system. This is because, the e-Hailing is easier to use and have a flexible in time of service [14]. Users also can stay at home while waiting for the service. So based on the modal shift result, it can conclude that users tends to shift from e-Hailing to public transport when the distance of travel and cost of travel increase. 


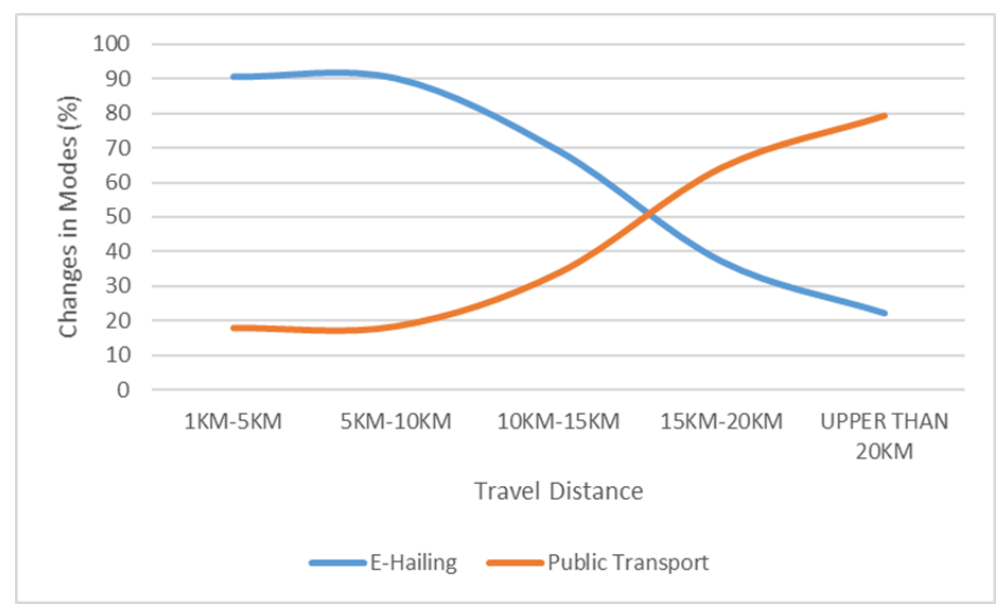

Fig 1 - Line graph of the effect of distance travel against changes in transportation mode

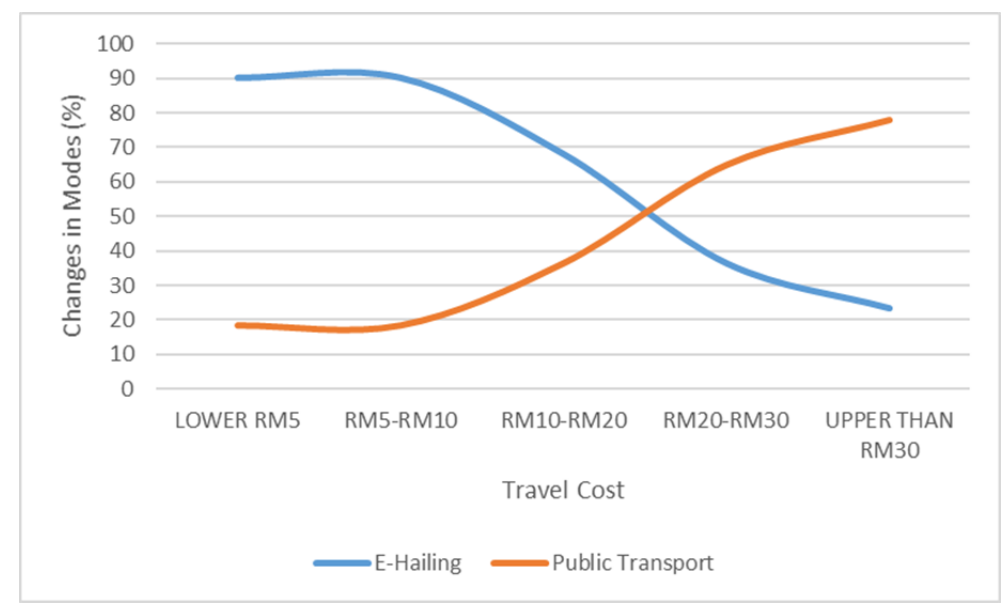

Fig. 2 - Line graph of the effect of cost travel against changes in transportation mode

\subsection{Regression Analysis}

From the analysis of the regression, the data that acquired be presented in Table 5. The table shows the $\mathrm{R}$ square value for the e-Hailing as a mode of choice is 0.384 . This value means that $38.4 \%$ of variance change between two of the dependent variables because of the change of the independent variable (travel cost and travel distance).

Table 5 - Regression statistics for e-hailing mode choice

\begin{tabular}{ccccc}
\hline \multicolumn{5}{c}{ Regression Statistics } \\
\hline Multiple R & R Square & Adjusted R Square & Standard Error & Observation \\
\hline 0.620 & 0.384 & 0.378 & 2.123 & 200
\end{tabular}

The next analysis is about the analysis of variance or also known as ANOVA. The ANOVA table also be analysed by SPSS and also be shown in ANOVA table. Table 6 shows the analysis data for the ANOVA that can get the sum of square, mean square, F statistic value and also the significant value. The variance value of residual is the value of means square error which is 61.447. After data been analysis also, the value of F-Test same which is 61.447. This value can be obtained by divided the mean square of regression with the mean square of residual.

Table 6 - ANOVA analysis for e-hailing mode choice

\section{ANOVA}




\begin{tabular}{cccccc}
\hline & Df & SS & MS & F & Significance F \\
\hline Regression & 2 & 553.804 & 276.902 & 61.447 & 0.000 \\
Residual & 197 & 887.751 & 4.506 & & \\
Total & 199 & 1441.555 & & & \\
\hline
\end{tabular}

From the analysis in Table 7, the result shows the analysis data that acquire from the coefficient analysis. At this analysis, the two variable that were set as independent variable are the distance travel and also the cost of travel. At this part, we can easily determine the major item that will be chosen as dependent variable. From this table, the value of coefficient for the distance travel $\left(\beta_{1}=0.525\right)$ and cost travel $\left(\beta_{2}=0.262\right)$ which this show the relationship in the value of significant 0.001 and 0.079 . So, from the analysis table below, it was shown that distance travel is the strongest item that be predict as major component for the user shift from public transport to e-Hailing system. This also were shown that e-Hailing users still use the system when increase of distance than public transport.

Table 7 - Regression coefficient for e-hailing system choice

\begin{tabular}{lllllll}
\hline & Coefficients & Standard Error & T-Stat & P-Value & Lower 95\% & Upper 95\% \\
\hline Distance & -0.525 & 0.150 & -3.501 & 0.001 & -0.821 & -0.229 \\
Cost & -0.262 & 0.148 & -1.764 & 0.079 & -0.554 & 0.031 \\
\hline
\end{tabular}

From the analysis of the regression, the data that acquired be presented in Table 8 . The table shows the $\mathrm{R}$ square value for the public transport as a mode of choice is 0.405 . This value means that $40.5 \%$ of variance change between two of the dependent variables because of the change of the independent variable (travel cost and travel distance).

Table 8 - Regression statistics for public transport mode choice

\begin{tabular}{ccccc}
\hline \multicolumn{5}{c}{ Regression Statistics } \\
\hline Multiple R & R Square & Adjusted R Square & Standard Error & Observation \\
\hline 0.636 & 0.405 & 0.399 & 2.077 & 200 \\
\hline
\end{tabular}

The next analysis is about the analysis of variance or also known as ANOVA. The ANOVA table also be analysed by SPSS and also be shown in ANOVA table. Table 9 shows the analysis data for the ANOVA that can get the sum of square, mean square, F statistic value and also the significant value. The variance value of residual is the value of means square error which is 66.97. After data been analysis also, the value of F-Test same which is 66.97. This value can be obtained by divided the mean square of regression with the mean square of residual.

Table 9 - Regression statistics for public transport mode choice

\begin{tabular}{cccccc}
\hline \multicolumn{6}{c}{ ANOVA } \\
\hline & Df & SS & MS & F & Significance F \\
\hline Regression & 2 & 578.028 & 289.014 & 66.97 & 0.000 \\
Residual & 197 & 850.167 & 4.316 & & \\
Total & 199 & 1428.195 & & & \\
\hline
\end{tabular}

From the analysis in Table 10, the result shows the analysis data that acquire from the coefficient analysis. At this analysis, the two variable that were set as independent variable are the distance travel and also the cost of travel. At this part, we can easily determine the major item that will be chosen as dependent variable. From this table, the value of coefficient for the distance travel $\left(\beta_{1}=0.535\right)$ and cost travel $\left(\beta_{2}=0.269\right)$ which this show the relationship in the value of significant 0.065 and 0.00 . So, from the analysis table below, it was shown that cost travel is the strongest item that be predict as major component for the user shift from e-Hailing system to public transport. This also were shown that eHailing users shift their mode choice to public transport when increase of cost travel.

Table 10 - Regression coefficient for public transport choice

Coefficients Standard Error $\quad$ T-Stat $\quad$ P-Value $\quad$ Lower $95 \% \quad$ Upper $95 \%$




\begin{tabular}{ccccccc}
\hline Distance & 0.269 & 0.145 & 1.853 & 0.065 & -0.017 & 0.555 \\
Cost & 0.535 & 0.147 & 3.643 & 0.000 & 0.245 & 0.825 \\
\hline
\end{tabular}

From the analysis data that obtain, it seems that distance travel plays an important role of factor that can affect the shifting process occur. The coefficient data show that the distance of travel has higher value than the cost of travel. Its show that users start to shift from e-Hailing to public transport when the distance of travel increase. A few of users also stay to use the e-Hailing as their alternative transport while the distance is increase. For the public transport, the shifting is occurring when the distance is decrease. Distance travel also shows the dominant factor in shifting. Changes in distance travel will affect the shifting from public transport to e-Hailing system. For the e-Hailing system mode of choice, it can conclude that the cost of travel is not the factor of shifting due to the value of significant shows. For the public transport mode of choice, the distance of travel is not the factor due to the not significant value.

Table 11 - Survey and modelling result for distance

\begin{tabular}{ccccc}
\hline & \multicolumn{2}{c}{ E hailing System } & \multicolumn{2}{c}{ Public Transport } \\
\hline Distance & Survey Result & Modelling Result & Survey Result & Modelling Result \\
\hline $1-5 \mathrm{~km}$ & 0.905 & 0.894 & 0.095 & 0.090 \\
$5-10 \mathrm{~km}$ & 0.9 & 0.893 & 0.1 & 0.191 \\
$10-15 \mathrm{~km}$ & 0.69 & 0.661 & 0.31 & 0.341 \\
$15-20 \mathrm{~km}$ & 0.37 & 0.461 & 0.63 & 0.611 \\
Upper $20 \mathrm{~km}$ & 0.225 & 0.326 & 0.775 & 0.740 \\
\hline
\end{tabular}

For the further analysis result, Table 11 shows the result on the different between the survey result with the modelling result. For the distance factor, there is a small different between survey and the modelling. As an example, the survey result for distance $1 \mathrm{~km}$ to $5 \mathrm{~km}$ is 0.905 but for the modelling result, the value is 0.8938 . The value of different is about 0.011. The table is divided into two part which are the result of e-Hailing and the result for public transport.

The illustration from Fig. 3 and Fig. 4 show the trend result for the e-Hailing choice probability and public transport choice probability. For the e-Hailing system, it was shown that the graph decreases when the distance increase. So, the negative trend for the e-Hailing system. But, for the public transport the graph shown the positive trend. This state that the number of respondents use the public transport increase when the distance travel increases from $1 \mathrm{~km}$ to upper than $20 \mathrm{~km}$.

For the next analysis result, the Table 12 show the result on the different between the survey result with the modelling result. For the cost factor, there is a small different between survey and the modelling. As an example, the survey result (e-Hailing System) for cost lower than RM5 is 0.9 but for the modelling result, the value is 0.8543 . The value of different is about 0.0457 . The table is divided into two part which are the result of e-Hailing and the result for public transport.

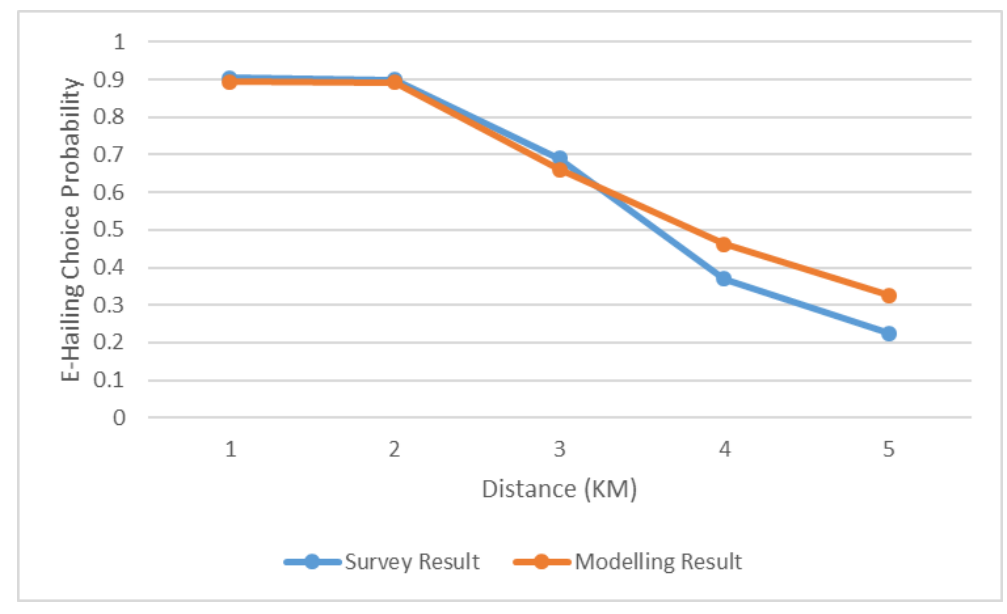

Fig. 3 - E-Hailing choice probability vs distance 


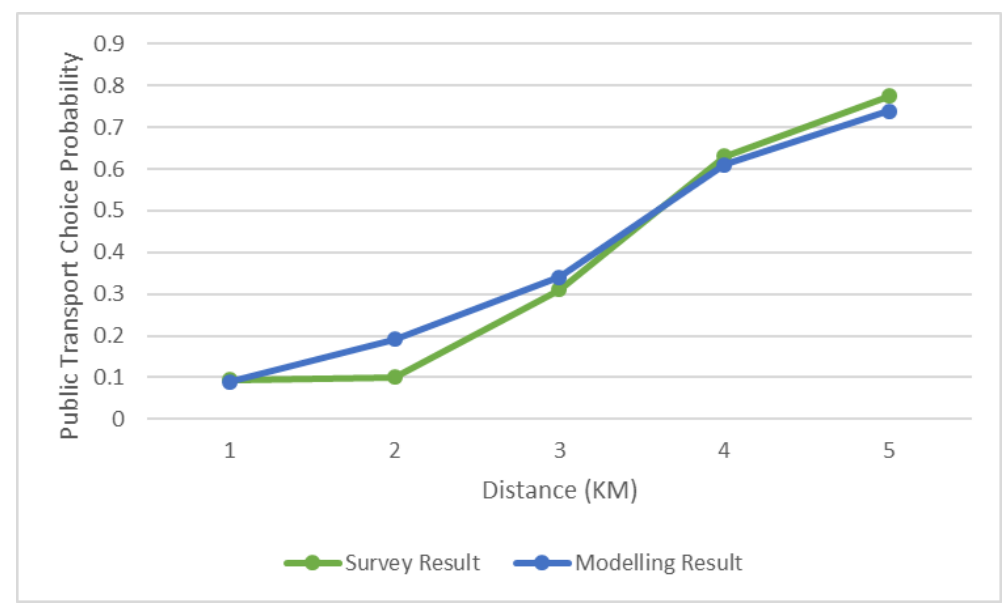

Fig 4 - Public transport choice probability vs distance

Table 12 - Survey and modelling result for cost

\begin{tabular}{ccccc}
\hline & \multicolumn{2}{c}{ e-hailing System } & \multicolumn{2}{c}{ Public Transport } \\
\hline Cost & Survey Result & Modelling Result & Survey Result & Modelling Result \\
\hline Lower RM5 & 0.9 & 0.854 & 0.1 & 0.154 \\
RM5-RM10 & 0.9 & 0.854 & 0.1 & 0.154 \\
RM10-RM20 & 0.685 & 0.604 & 0.315 & 0.401 \\
RM20-RM30 & 0.37 & 0.427 & 0.63 & 0.662 \\
Upper RM30 & 0.225 & 0.291 & 0.775 & 0.775 \\
\hline
\end{tabular}

The illustration from Fig. 5 and Fig. 6 show the trend result for the e-Hailing choice probability and public transport choice probability. For the e-Hailing system, it was shown that the graph decreases when the cost increase. So, the negative trend for the e-Hailing system. But, for the public transport the graph shown the positive trend. This state that the number of respondents use the public transport increase when the cost travel increases from lower than RM5 to upper than RM30.

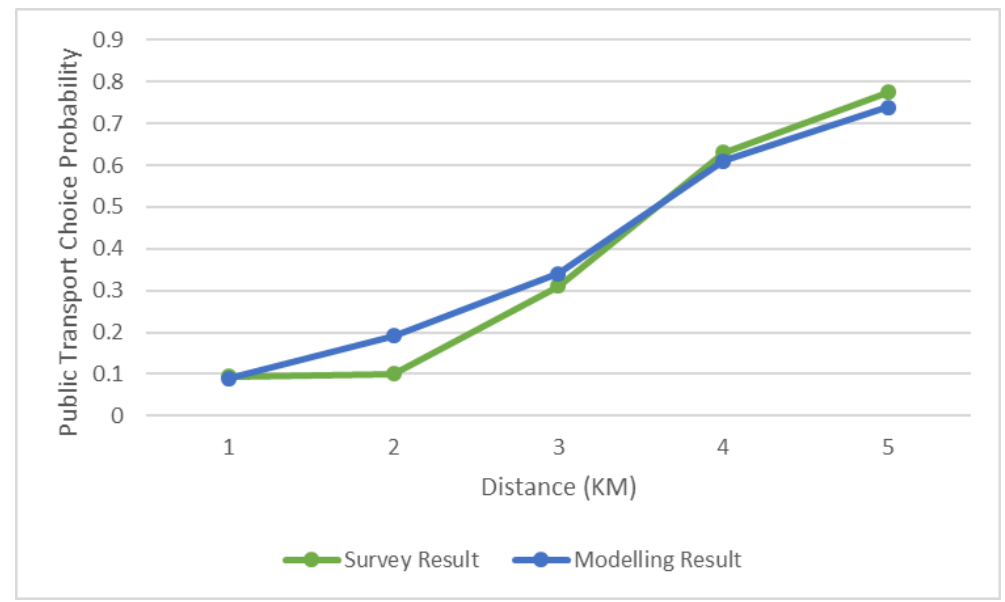

Fig. 5 - e-Hailing choice probability vs cost 


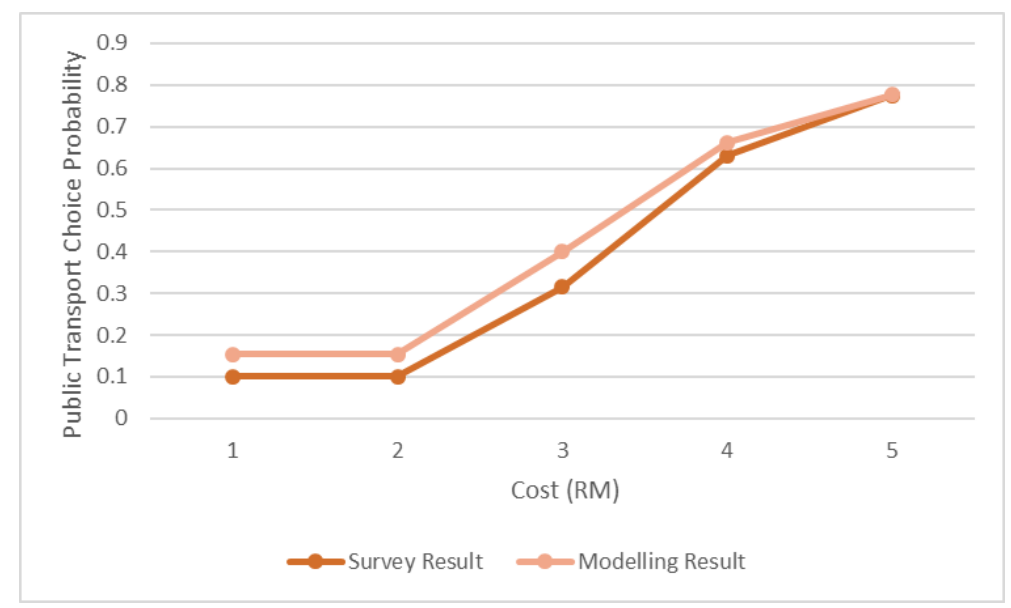

Fig. 6 - Public transport choice probability vs distance

\section{Conclusion}

This research is conducted to determine the contributing factor that effect to use e-Hailing as alternative transport. The method of collecting data is by using questionnaire at the Johor Bahru as the location of the survey because of the popularities of the e-Hailing system at that area. The contributing factors shown the major effect of using e-Hailing is about the exposure of the e-Hailing system in our community. This can be proved because of the means score for the statement about e-Hailing exposure have a highest rank than the other. The community actually do not know about the presence of e-Hailing that have the same function like public transport. In addition, the community also do not know on how to use the e-Hailing service in their smart phone. The second statement that also has high in mean score are about the statement about the easiness of using the e-Hailing system. The service of the e-Hailing system is easier than the using of public transport. This is because users that use the service can only wait at their home while waiting the eHailing arrive. These are the factors that will contribute to using the e-Hailing system. The modal shift between eHailing system and public transport demonstrates that the main factor of shifting is the distance travel. When the travel distances increase, the shifting will occur for the public transport shift to e-Hailing system. The distance travel also becomes a dominant factor that can make the user of e-Hailing stand for it. Furthermore, the modal shift is also able to know the shifting point that occur for distance travel and cost of travel. As a conclusion, the objectives of this research have been achieved successfully. The results of this study will contribute to the alternative transport users in improving and assist them to make their choice in choosing the better alternative transport.

\section{Acknowledgement}

Authors would like to thanks Ministry of Higher Education that gave the funding of Fundamental Research Grant Scheme (FRGS) for Phase 12020 (K332), Research Management Centre (RMC) and Registrar Office, UTHM those gave financial support. Also, thanks to Faculty of Civil and Environmental Engineering, UTHM and Smart Driving Research Center (SDRC) for support and providing facilities to accomplish the study.

\section{References}

[1] Andrea M. M. A. \& Chadwick Co S. S. (2017). Out with the old, in with the new: A study on the vehicle hailing preferences of Filipino taxi riders based on participation intent. International Journal of Real Estate Studies, 11(1), $1-7$

[2] Tian X., Geng Y., Zhong S., Wilson J., Gao C., Chen W., Yu Z. \& Hao H. (2018). A bibliometric analysis on trends and characters of carbon emissions from transport sector. Transportation Research Part D: Transport and Environment, 59, 1-10

[3] Yaacob N. F. F., Mat Yazid M. R., Abdul Maulud K. N. \& Ahmad Basri N. E. (2020). A review of the measurement method, analysis and implementation policy of carbon dioxide emission from transportation. Sustainability, 12(5873), 1-22

[4] Fang Z., Su R. \& Huang L. (2018). Understanding the effect of an e-hailing app subsidy war on taxicab operation zones. Journal of Advanced Transportation, 2018, 7687852

[5] Gan J, An B., Wang H., Sun X. \& Shi Z. (2013). Optimal pricing for improving efficiency of taxi systems. Proceedings of the Twenty-Third International Joint Conference on Artificial Intelligence, Beijing, pp. 2811-2818

[6] Ambak K., Kasvar K. K., Daniel B. D., Prasetijo J. \& Abd Ghani A. R. (2016). Behavioral intention to use public transport based on theory of planned behavior. MATEC Web Conference, 47, 03008 
[7] Paronda A. G. A. \& Gaabucayan-napalang M. S. (2016). An exploratory study on Uber, GrabCar, and conventional taxis in Metro Manila. Conference of Sustainable Built Environment, Manila

[8] Vivoda J. M., Harmon A. C., Babulal G. M. \& Zikmund-Fisher B. J. (2018). E-hail (rideshare) knowledge, use, reliance, and future expectations among older adults. Transportation Research Part F: Traffic Psychology Behaviour, 55, 426-434

[9] Ruangkanjanases A. \& Techapoolphol C. (2018). Adoption of e-hailing applications: A comparative study between female and male users in Thailand. Journal of Telecommunication, Electronic and Computer Engineering, 10(1), 43-48

[10] Sahir A. \& Marzuki A. (2018). Urban mobility using e-hailing in the historic city of Melaka, Malaysia: Preliminary findings. International Conference on Built Environment in Developing Countries, Kuching

[11] Abd Ali Dawood S. \& Rahmat R. A. O. K. (2015). Factors that affect cycling transportation mode for postgraduate students at Universiti Kebangsaan Malaysia by logit method. Jurnal Kejurutereraan, 27, 1-7

[12] Muley D., Bunker J. \& Ferreira L. (2009). Investigation into travel modes of TOD users: Impacts of personal and transit characteristics. International Journal of ITS Research, 7(1), 3-13

[13] Satiennam T., Jaensirisak S., Satiennam W. \& Detdamrong S. (2016). Potential for modal shift by passenger car and motorcycle users towards Bus Rapid Transit (BRT) in an Asian developing city. IATSS Research, 39(2), 121129

[14] Aarhaug J. (2010). Taxis as a Part of Public Transport Sustainable Urban Transport, Technical Document No. 16. European Transport Research Review 7:17. http://www.sutp.org 